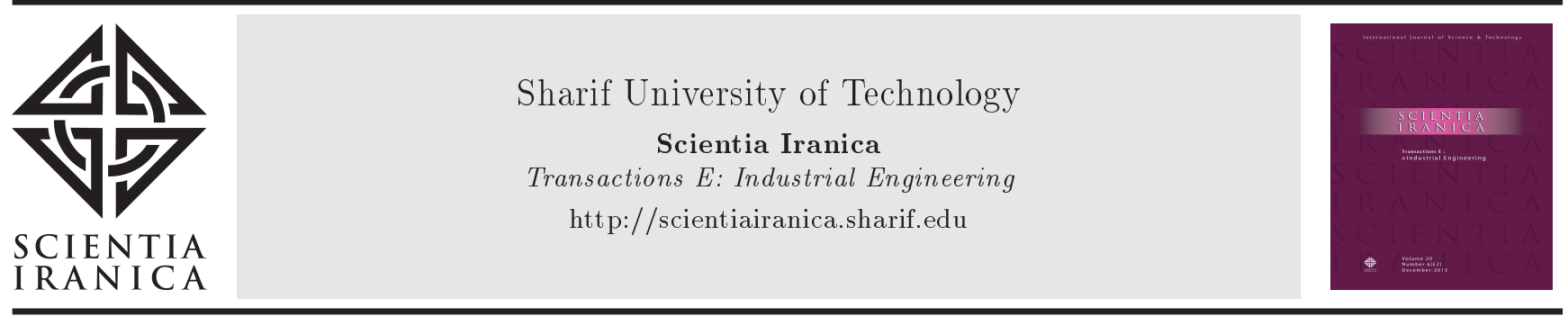

\title{
Efficiency assessment of medical diagnostic laboratories using undesirable sustainability indicators: A network data envelopment analysis approach
}

\author{
N. Ghafari Someh ${ }^{a}$, M.S. Pishvaee ${ }^{b, *}$, S.J. Sadjadi ${ }^{b}$, and R. Soltanic \\ a. Department of Industrial Engineering, Science and Research Branch, Islamic Azad University, Tehran, Iran. \\ b. School of Industrial Engineering, Iran University of Science and Technology, Tehran, Iran. \\ c. Department of Industrial Engineering, Faculty of Engineering, KHATAM University, Tehran, Iran.
}

Received 10 May 2019; received in revised form 4 June 2020; accepted 20 July 2020

KEYWORDS
Network data
envelopment analysis;
Sustainable
development;
Medical diagnostic
laboratories;
Efficiency evaluation;
Additional data
(desirable and
undesirable).

\section{KEYWORDS}

Network data

Sustainable

development;

Medical diagnostic

laboratories;

Efficiency evaluation;

Abstract. The current study aims to assess the performance of health systems to assist health decision-makers. Medical diagnostic laboratories are one of the most important sectors in the healthcare system of all countries. This is the reason why assessment of the performance of medical diagnostic laboratories is of particular importance. To this end, this study proposed Network Data Envelopment Analysis (NDEA) model to assess the performance of the medical diagnostic laboratories and evaluate the efficiency of the system based on sustainable development indicators. The proposed model was designed based on the internal structure of the medical diagnostic laboratory comprised of three main laboratory processes including the pre-test, test, and post-test with a combination of both desirable and undesirable additional inputs and outputs. The proposed model is a multiplicative Data Envelopment Analysis (DEA) approach used for estimating and decomposing the efficiency of the system under study. In addition, a heuristic method was used as a suitable solution to convert a multiplicative NDEA approach into an equivalent linear program. In this study, the evaluation criteria were obtained using fuzzy TOPSISDelphi method. The performance of the proposed model was evaluated in a real study conducted in Iran. The computational results confirmed the applicability of the proposed model in determining the most efficient laboratory based on the undesirable sustainability indicators.

(C) 2022 Sharif University of Technology. All rights reserved.

\section{Introduction}

In recent years, the health status of most countries, especially in the case of epidemic diseases, has faced a great challenge [1]. Among these serious concerns are the inequality in access to health services, changes

*. Corresponding author. Fax: +9821 73225098

E-mail addresses: niloufar.ghaffari@srbiau.ac.ir (N.

Ghafari Someh); pishvaee@iust.ac.ir (M.S. Pishvaee);

sjsadjadi@iust.ac.ir (S.J. Sadjadi); r.soltani@khatam.ac.ir

(R. Soltani)

doi: $10.24200 /$ sci.2020.53534.3288 in the care quality and safety, lack of health facilities, and rising costs of health care services [2]. According to the global standards, approximately $10 \%$ of the total healthcare expenditure is spent on the laboratory services [3]. In addition to the economic aspects, environmental and social aspects are of significance such that the leading diagnostic laboratory services have increasingly emphasized the importance of managing and controlling the social, environmental, and economic performance. In this regard, managers' attention to sustainability factors in diagnostic laboratories can effectively affect three sustainability factors, namely the social, environmental, and economic factors, in 
promoting the health community. To be specific, an essential need for the performance assessment of diagnostic laboratories as one of the most important and largest providers of health care services is felt due to their considerable role in health care systems.

The performance of medical diagnostic laboratories can be evaluated by determining their efficiency, i.e., the strength and weakness or the efficiency and inefficiency of such units. In this way, the units can eliminate their defects and emphasize their strength [4]. These laboratories can prevent errors by improving their performance, thus ensuring the accuracy of laboratory results. This approach primarily aims to provide high-return services. Even a negligible upgrade in the lab improvement programs will considerably aid attentiveness towards serving people. Obviously, a suitable tool is required to analyze the effectiveness of diagnostic laboratories. One of the most suitable and effective tools in this field is Data Envelopment Analysis (DEA), first introduced by Charnes [5], which is a mathematical method for measuring the relative efficiency of Decision-Making Units (DMUs).

The traditional DEA models disregard the internal operations or structure of the DMUs, typically referring to each DMU as a "black box" with a single process that converts multiple inputs into multiple final outputs. These approaches cause incorrect performance scores or misleading results with respect to the system with a complex internal structure $[6,7]$. To counter the constraints of the traditional DEA models, a DEA network was proposed in [8]. The structure of DMUs as a system containing a network of sub-DMUs with intermediate measures was taken into account. They are usually used as the sources of production and sometimes, as consumable resources [9].

DEA models face several limitations the most important of which is the situation where the process produces undesirable factors. The development of undesirable factors such as production of infectious waste, especially in the health services sector, is of particular importance. Färe et al. [10] pointed to the role of undesirable factors in evaluating the performance efficiency for the first time.

The current research provides a brief summary of the recent conducted studies that have employed the DEA method to evaluate the performance of health care systems in different sectors.

A review of the related literature reveals that a significant number of studies attempt to evaluate the performance of health care systems in different sectors, yet many studies on the hospital performance evaluation are available [11]. Among the review papers published in the field of hospital performance evaluation, the study conducted by Nayar and Ozcan [12] is of importance which examined the qualitative performance criteria using a sample of Virginia hospitals.
The performance scores of hospitals were calculated using DEA. The studies by Audibert et al. [13] and Varabyova and Schreyögg [14] evaluated different aspects of health care performance. Audibert et al. [13] first highlighted the increased access to health care services for the rural population and then, assessed the performance of the health care system. In this study, 24 urban hospitals in Weifang (Shandong) were surveyed from 2000 to 2008. They measured the efficiency of the mentioned urban hospitals through a two-step approach. Varabyova and Schreyögg [14] compared the technical efficiency of the hospital departments. To this end, they used the unbalanced panel data of the OECD countries from 2000 to 2009 and estimated the technical efficiency of the hospital departments using non-parametric DEA and parametric Stochastic Frontier Analysis (SFA). The internal and external validity of their findings was measured by Spearman's rank correlation coefficient. Of note, they analyzed only one aspect of efficiency, i.e., technical efficiency. A review of the papers revealed that many health studies were published in 2014 a number of which have been mentioned here. The analysis of the effectiveness of health care systems plays a key role in determining the public health costs and health assessment. A study by Leleu et al. [15] is an important example related to this subject. The present study considered two issues to describe the factors affecting the financial sustainability including: (a) The costs patients cannot afford for hospital services and (b) Internal management. The main objective of this study was to evaluate the effect of these two factors on the profitability of hospitals. In this regard, the DEA method was employed to measure the input inefficiencies in the manufacturing process, considering 138 hospitals in Florida in 2005. In the same year, two studies were conducted to evaluate the European health system. Popescu et al. [16] in the first study evaluated the efficiency of the European health systems. To this end, they employed the DEA approach to evaluate the efficiency of health systems. They remarked that Romania enjoyed the benefits of an inappropriate health system. Even though the Romanian health system has made a significant progress during the past two decades, some of its sectors have still lower quality than the average of other European countries do. Therefore, it can be concluded that the system is not yet able to provide appropriate services for its citizens. In another study, Asandului et al. [17] evaluated the performance of the public health systems in Europe based on a nonparametric DEA method and assessed the statistical data for 30 European countries in 2010. The latest study in 2014 was conducted by Al-Refaie et al. [18] who calculated the average waiting time for patients of Emergency Department (ED) and determined the number of physicians and nurses in the ED, considering a cellular service system. In their 
study, the performance evaluation was simulated over a month (672 hours) with 10 replications. Then, the best scenario was presented using aggressive formulation in DEA. Chowdhury and Zelenyuk [19] examined the performance of hospital services in Ontario, Canada, employed the DEA to evaluate efficiency, and truncated regression estimation with double-bootstrap to test the importance of explanatory variables. Campos et al. [20] applied the input-oriented DEA approach to examine the efficiency of health systems in Spain (Autonomous Communities). The current study primarily aims to analyze the efficiency of public resources. Considering the essential need for efficiency improvement in the health care, Johannessen et al. [21] examined the effectiveness of Full-Time Doctors (FTE) in hospitals based on panel analysis and DEA. The efficiency of the physician workforce as well as the impact of personnel workforce at 19 Norwegian hospitals were studied from the year 2001 to 2013. However, the network structure was not studied. Khushalani and Ozcan [22] investigated the returns of the United States hospital over five years from 2009 to 2013 . To this end, they took into account the dynamic DEA with network structure to perform the performance evaluation of different hospital departments such as the medical/surgical care (patient visits, surgeries, and discharges) and quality. Patra and Ray [23] examined the efficiency of hospital systems. In their study, the Malmquist productivity index based on the DEA was applied to determine both productivity and efficiency of an Indian hospital system. They analyzed the efficiency of several hospital departments and suggested some improvement alternatives. Şahin and İlgün [24] in another study in the field of health services presented an assessment of the efficiency of dental services at the provincial level in Turkey. The population under study consisted of hospitals and dental care centers under the Ministry of Health located in 81 provinces of Turkey. The efficiency of oral and dental centers was evaluated using DEA method. Motevali Haghighi and Torabi [25] established a mixed sustainability-resilience framework to evaluate Hospital Information System (HIS) from the viewpoint of mixed sustainability-resilience. They remarked that this model could be applied to enhance their performance. In a real case study, a DEA model was applied to evaluate the HIS performance. Peykani et al. [26] proposed a novel fuzzy DEA model based on general fuzzy measure to determine the attitude of DMUs based on the optimistic-pessimistic parameters. In this regard, they evaluated the efficiency of 38 hospitals in the United States to clarify the practical applications of this approach on a real data set. In order to understand the variation in access to early prenatal care in a more complete manner, Thorsen et al. [27] identified unique compositions of Community Health Centers (CHCs). They focused on the DEA approach to evaluate the operational efficiency of the CHCs. Abolghasem et al. [28] reported the data of the healthcare systems indicators in 120 countries from 2010 to 2017 and then, evaluated their efficiency based on the DEA method. It should be kept in mind that laboratory services are one of the important constituents that determines the quality of any health care system. This is the main reason why performance evaluation of the laboratory fields has gained significance. However, very few studies have been conducted in this area. One of the papers published on the performance evaluation of laboratories is the study conducted by Chawla et al. [29]. Quality indicators in the clinical laboratory were considered useful tools for continuously improving the laboratory services. They primarily aimed to design and evaluate the quality indicators over time in order to improve the performance of the laboratories. To this end, different qualitative indicators were carefully studied. The indicators under study were the properties of a biochemistry laboratory of the hospital in New Delhi that played a key role in the quality improvement of laboratory services as well as patient health care by taking corrective measures over a certain time period. Bakar et al. [30] conducted another study on the laboratories. They reviewed the efficiency of public hospital laboratories in identifying the degree of doctors' satisfaction. They collected their required data from interviews with two senior laboratory administrators and 30 doctors of two laboratories in Malaysia. The interview was comprised of two sets of structured questionnaires in two dimensions, namely Doctor Satisfaction Dimension (DSD) and Supply Chain Inputs (SCI).

In recent studies, only single-stage DEA models have been used in a traditional way. As a result, the health systems were analyzed as if they were characterized by a black-box nature, i.e., without revealing any information about their internal mechanism. In this respect, the current study developed this concept in three-stage health systems to overcome the mentioned limitation. Another novelty of the proposed approach is the application of both desirable and undesirable sustainability indicators to evaluate the performance of the healthcare facilities, thus filling a considerable gap in the literature. In this research, a threestage laboratory was designed and then, sustainability indicators (economic, environmental, and social) were utilized to evaluate the efficiency of diagnostic laboratories. Of note, the undesirable factors in the data are of importance in the analysis. Next, a heuristic method was proposed and the multiplicative Network Data Envelopment Analysis (NDEA) approach was converted into an equivalent linear program. In addition, a real case study was conducted in Iran indicating the applicability of the proposed approach in practice. 
The most significant contributions of this study are highlighted below:

- Application of undesirable sustainability indicators (social, economic, and environmental) in the proposed approach;

- Performance assessment considering three major laboratory processes (pre-testing, testing, and posttesting) in a NDEA model;

- Investigation of a real case study on the diagnostic laboratories, which have not been explored earlier in spite of the importance of diagnostic laboratories in the field of health services;

- Establishment of a heuristic model to convert a multiplicative NDEA approach into an equivalent linear program.

This paper is organized as follows. Section 2 discusses the research methodology. In this section, the indicators are identified using fuzzy TOPSIS-Delphi method and the mathematical modeling of the problem is elaborated. Then, a heuristic approach is introduced to solve the nonlinear program. Section 3 further discusses the proposed model based on a real case study on the efficiency of 25 private medical diagnostic laboratories in Iran to demonstrate the applicability and partibility of the proposed model. Section 4 analyzes the obtained results. Finally, Section 5 concludes the paper and suggests some related topics for further research.

\section{Methodology}

Since our case study is a medical diagnostic laboratory, the effective factors are quantitative data. Despite the fact that many variables can be considered, there are no relative data in most cases. This is one of the real-world problems that makes variables difficult to determine. In this respect, appropriate selection of variables is of high significance. The methodology used in this study was designed in two steps. Given that the variables are not identified and there is no structural and theoretical guidance in the first step, the factors affecting each dimension of the model were determined by analyzing the organizational documents, library studies, observation, and interview. Then, the Fuzzy TOPSIS approach was employed to select the optimal indicators among the available indicators. Finally, experts' opinions and Delphi method were taken into account to reach a consensus about the influential factors and evaluate and screen the findings of this stage. In the second step, a NDEA approach was designed to evaluate the performance of laboratories. The methodology is illustrated in two steps in Figure 1.

\subsection{Identification of indicators using qualitative studies}

In this subsection, first, two methods of documentation and observation were employed to find the most important indicators in the laboratory field and compile them. Some of these indicators are available in the

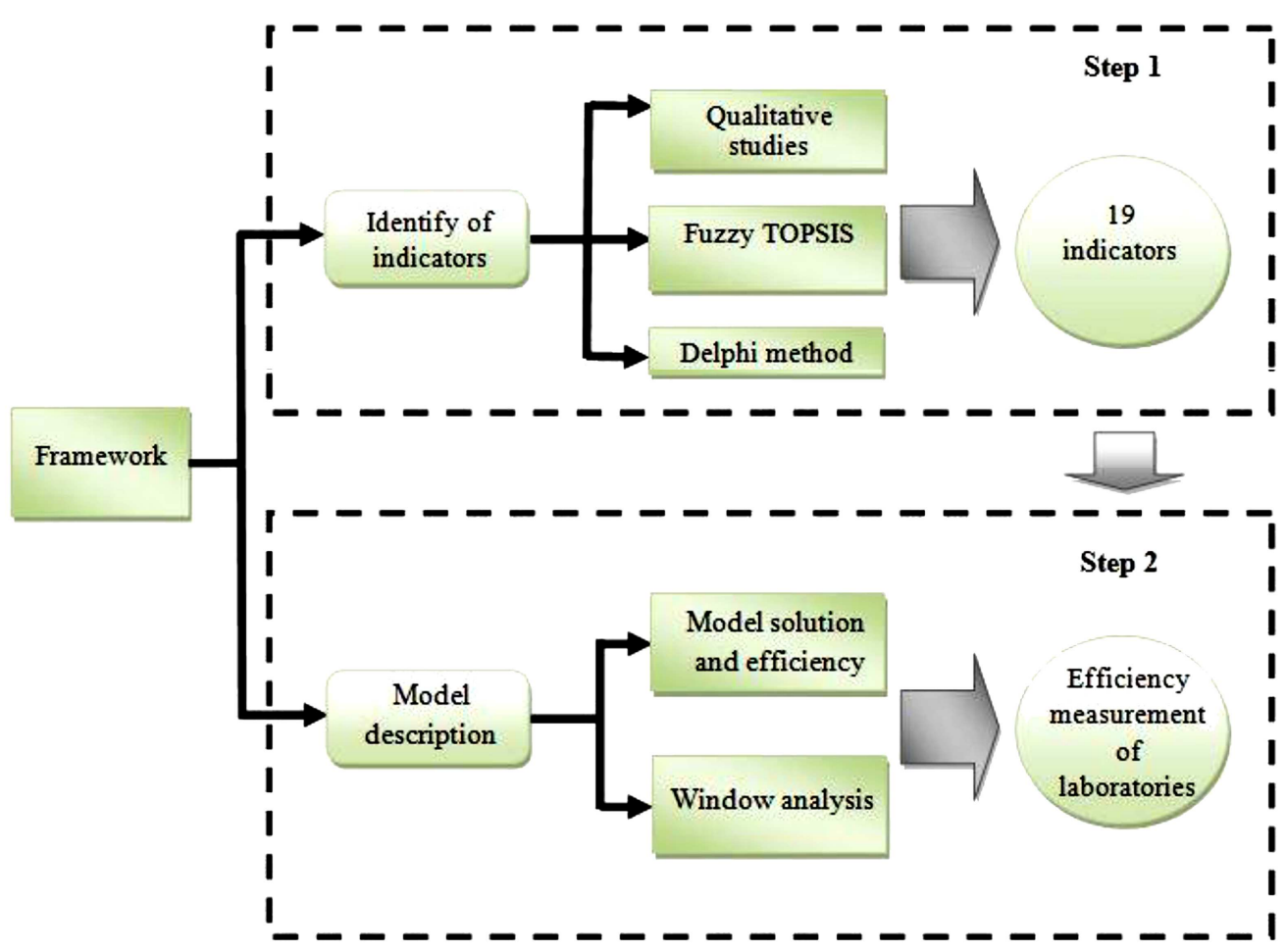

Figure 1. Steps of methodology. 
Table 1. Indicators effective in evaluating the performance of medical diagnostic laboratories.

\begin{tabular}{cl}
\hline Row & \multicolumn{1}{c}{ Indicator } \\
\hline 1 & Sum of the scores of the laboratory standards \\
2 & Garbage weight \\
3 & Average sample transfer time \\
5 & Number of patients' admitted \\
6 & Number of active experiments \\
7 & Test response time \\
8 & Number of false tests \\
9 & Available space for service \\
10 & Average waiting time for sampling \\
11 & Cost of consumables \\
12 & Staff wage \\
13 & Number of responses of the prepared tests \\
14 & Safety cost of test unit \\
15 & Number of kits \\
16 & Safety cost of sampling unit \\
17 & Lab profit \\
18 & Income from admission \\
19 & Cost of laboratory space and land value \\
20 & Number of samples \\
21 & Cost of staff welfare \\
\hline &
\end{tabular}

form of documents and articles. Then, by attending laboratories, we got the overall effective factors in the laboratory processes through the observation of the organization. The appropriate indicators are listed in Table 1.

\subsection{Fuzzy TOPSIS technique}

In this step, the fuzzy TOPSIS method is used as an approach to deal with complex choice systems between different indicators to evaluate the improvement. In other words, fuzzy TOPSIS makes the comparison between the indicators feasible [31]. It also creates consistent and systematic criteria based on selecting the best indicators with the shortest distance from the positive ideal solution as well as the farthest distance from the negative ideal solution. While the positive ideal solution is one of the most advantageous indicators of all, the negative ideal solution is one of the lowest advantageous ones. These indicators are ranked according to their relative proximity to the ideal solutions. The objective here is to prioritize the optimal indicators such that they are closest to the positive ideal solution and farthest from the negative ideal solution [32]. Fuzzy TOPSIS includes the following steps:

Step 1: Definition of linguistic variables. The questionnaire was designed aimed at obtaining the experts' opinions about the extent to which they would reach a consensus about the model criteria. The experts would express their consent through verbal variables such as very low, low, medium, high, and very high. Since different individuals' traits affect their mental interpretation of the qualitative variables, the experts with the same mindsets would respond to the questions by defining the range of qualitative variables. These variables are defined in the form of triangular fuzzy numbers, as shown in Table 2. As observed in this table, the defuzzication value is calculated by $x=$ $m+\frac{\beta-\alpha}{4}$.

Step 2: Establishment of decision matrix to evaluate the indicators: In this step, 20 experts at medical diagnostic laboratories study the identified indicators based on the linguistic variables.

Step 3: Calculation of the normalized decision matrix through $\tilde{R}=\left[\tilde{r}_{i j}\right]_{m \times n}, i=1,2, \ldots, n, j=1,2, \ldots, m$ where $m$ is the number of indicators and $n$ the number of experts.

Step 4: Calculation of the weighted normalized decision matrix. The weighted normalized value: $\tilde{V}=$ $[\tilde{v}]_{i j}, i=1,2, \ldots, n, j=1,2, \ldots, m$ is calculated as: $\tilde{v}=w_{i j} \times v_{i j}$. Here, $W_{i j}$ stands for the weighted value based on the opinions of experts.

Step 5: Definition of the positive ideal solution $\left(A^{+}\right)$ and negative ideal solution $\left(A^{-}\right)$. Here, both positive and negative ideal values suggested by Chen [33] are taken into consideration.

Table 2. Triangular fuzzy numbers of Linguistic variables.

\begin{tabular}{|c|c|c|}
\hline Linguistic variables & Triangular fuzzy number & Defuzzification value \\
\hline Very low effect & $(1,1,3)$ & 0.75 \\
\hline Low effect & $(1,3,5)$ & 0.5625 \\
\hline Medium effect & $(3,5,7)$ & 0.3125 \\
\hline High effect & $(5,7,9)$ & 0.0625 \\
\hline Very high effect & $(7,9,9)$ & 0.0625 \\
\hline
\end{tabular}


Table 3. Ranking of indicators.

\begin{tabular}{|c|c|c|c|c|c|}
\hline Row & Indicator & $\begin{array}{c}\text { The distance to the } \\
\text { positive ideal }\end{array}$ & $\begin{array}{l}\text { he distance to the } \\
\text { negative ideal }\end{array}$ & $C$ & Rank \\
\hline 1 & Sum of the scores of the laboratory standards & 25.085 & 0.921 & 0.035 & 1 \\
\hline 2 & $\begin{array}{l}\text { Cost of laboratory space } \\
\text { and land value }\end{array}$ & 25.21 & 0.808 & 0.031 & 2 \\
\hline 3 & Average sample transfer time & 25.243 & 0.776 & 0.03 & 3 \\
\hline 4 & Garbage weight & 25.26 & 0.758 & 0.029 & 4 \\
\hline 5 & Number of patients' admitted & 25.266 & 0.754 & 0.029 & 5 \\
\hline 6 & Number of active experiments & 25.288 & 0.734 & 0.028 & 6 \\
\hline 7 & Number of false tests & 25.302 & 0.722 & 0.028 & 7 \\
\hline 8 & Number of samples & 25.356 & 0.669 & 0.026 & 8 \\
\hline 9 & Available space for service & 25.367 & 0.658 & 0.025 & 9 \\
\hline 10 & Correct number of tests & 25.466 & 0.644 & 0.022 & 10 \\
\hline 11 & Number of kits & 25.480 & 0.606 & 0.022 & 11 \\
\hline 12 & Average waiting time for sampling & 25.501 & 0.599 & 0.02 & 12 \\
\hline 13 & Staff wage & 25.566 & 0.576 & 0.019 & 13 \\
\hline 14 & Cost of staff welfare & 25.599 & 0.555 & 0.019 & 14 \\
\hline 15 & Test response time & 25.607 & 0.543 & 0.017 & 15 \\
\hline 16 & responses of the prepared tests & 25.666 & 0.520 & 0.017 & 16 \\
\hline 17 & Income from admission & 25.676 & 0.511 & 0.016 & 17 \\
\hline 18 & Cost of consumables & 25.702 & 0.498 & 0.013 & 18 \\
\hline 19 & Safety cost of test unit & 25.756 & 0.477 & 0.013 & 19 \\
\hline 20 & Lab profit & 25.768 & 0.465 & 0.011 & 20 \\
\hline 21 & Safety cost of sampling unit & 25.789 & 0.413 & 0.011 & 21 \\
\hline
\end{tabular}

Step 6: Calculation of the total distances of each of the indicators from both fuzzy positive and fuzzy negative ideals. If $\tilde{A}=\left(a_{1}, a_{2}, a_{3}\right)$ and $\tilde{B}=\left(b_{1}, b_{2}, b_{3}\right)$ are two fuzzy numbers, the distance between these two fuzzy numbers is obtained as:

$$
(\tilde{A}, \tilde{B})=\sqrt{\frac{1}{3}\left[\left(b_{1}-a_{1}\right)^{2}+\left(b_{2}-a_{2}\right)^{2}+\left(b_{3}-a_{3}\right)^{2}\right]} .
$$

Depending on how the distance between the two fuzzy numbers is calculated, the distance between each of the positive and negative and ideal components is obtained as:

$$
d_{i}^{+}=\sum_{j=1}^{n} d\left(\tilde{v}_{i j}-\tilde{v}_{i j}^{+}\right), \quad i=1,2, \ldots, m \quad j=1,2, \ldots, n,
$$

and:

$$
d_{i}^{-}=\sum_{j=1}^{n} d\left(\tilde{v}_{i j}-\tilde{v}_{i j}^{+}\right), \quad i=1,2, \ldots, n \quad j=1,2, \ldots, m .
$$

Step 7: Calculation of the relative closeness of each indicator to the ideal solution which can be obtained by:

$$
c_{i}=\frac{D_{i}^{-}}{D_{i}^{-}+D_{i}^{+}} \quad i=1,2, \ldots, m .
$$

Step 8: Ranking of the indicators: Based on the order of the decreasing $C$ value, the existing indicators can be ranked. In other words, each indicator with a larger $C$ value will be considered more important. The results of ranking of indicators are shown in Table 3 .

\subsection{Delphi method}

The Delphi method is the most effective method for identification of the indices. It is an iterative process to collect and modify judgments of experts using a series of data collection. This method is especially useful for healthcare providers where evaluation standards are not available. In this step, experts identify the required indicators based on their rankings obtained from the Fuzzy TOPSIS method.

The effective criteria of the three laboratory processes (pre-test, test, and post-test) were obtained from the Delphi method to extract the factors using the ranking of the indicators obtained in Table 3, as illustrated in the following steps: 
Table 4. The Likert scale.

\begin{tabular}{ccccc}
\hline $\mathbf{1}$ & $\mathbf{2}$ & $\mathbf{3}$ & $\mathbf{4}$ & $\mathbf{5}$ \\
\hline Very low effect & Low effect & Medium effect & High effect & Very high effect \\
\hline
\end{tabular}

Step 1: All group members received the first questionnaire which was designed in a semi-structured manner based on the information given in Table 3 . Next, a second questionnaire was designed based on the data extracted from the first one:

Step 2: Members of the Delphi team were given a questionnaire and asked to determine the importance of the criteria based on Likert scale in Table 4. Starting with this step onwards, we aim to reach a consensus among the respondents;

Step 3: The average value of each criterion was calculated based on the data from the first Delphi stage. The experts were given a third questionnaire set, and the data were processed in a usual way similar to the previous step. Here, respondents were given the option to change their previous opinions and check and evaluate other experts' opinions, thus channeling the process towards reaching a mutual consensus. Table 5 shows the final performance indicators in the field of diagnostic labs based on the Delphi method.

\subsection{Model description}

\subsubsection{Three-stage process}

The three stages mentioned in Figure 2 were taken into consideration to define each time period as a DMU and to denote it as $D M U_{j}(j=1,2, \ldots, n)$. It actually simulates a medical diagnostic lab in the real world. The laboratory consists of three main processes, namely the pre-testing, testing, and post-testing. The first, second, and third stages are the reception, sampling and testing, and test results units, respectively. In the reception unit, both desired and undesired inputs denoted by $x_{i_{1 j}}\left(i_{1}=1,2, \ldots, I_{1}\right)$ and $x_{i_{2} j}\left(i_{2}=1,2, \ldots, I_{2}\right)$, respectively, were taken into account. In addition, both of the desired and undesired outputs were referred to as the
Table 5. Effective indicators for the performance evaluation of medical diagnostic laboratories.

\begin{tabular}{cl}
\hline Row & \multicolumn{1}{c}{ Indicator } \\
\hline 1 & Sum of the scores of the laboratory standards \\
2 & Garbage weight \\
4 & Average sample transfer time \\
5 & Number of the patients' admitted \\
6 & Number of active experiments \\
7 & Number of false tests \\
8 & Available pace for service \\
9 & Staff wage \\
10 & Number of kits \\
11 & Income from admission \\
12 & Cost of consumables \\
13 & Safety cost of test unit \\
14 & Safety cost of sampling unit \\
15 & Average waiting time for sampling \\
16 & Test response time \\
17 & Number of responses of the prepared tests \\
18 & Lab profit \\
19 & Number of samples \\
\hline
\end{tabular}

additional outputs denoted by $y_{r_{1 j}}\left(r_{1}=1,2, \ldots, R_{1}\right)$ and $y_{r_{2} j}\left(r_{2}=1,2, \ldots, R_{2}\right)$, respectively. The intermediate measures between the the reception unit and the sampling-and-testing unit can be obtained from $z_{d_{1 j}}\left(d_{1}=1,2, \ldots, D_{1}\right)$. The additional inputs to the sampling-and-testing unit are represented by $x_{i_{3 j}}\left(i_{3}=1,2, \ldots, I_{3}\right)$. The intermediate measures of the sampling-and-testing unit and the test result unit can be represented by $z_{d_{2} j}\left(d_{2}=1,2, \ldots, D_{2}\right)$. The additional outputs in the sampling-and-testing unit

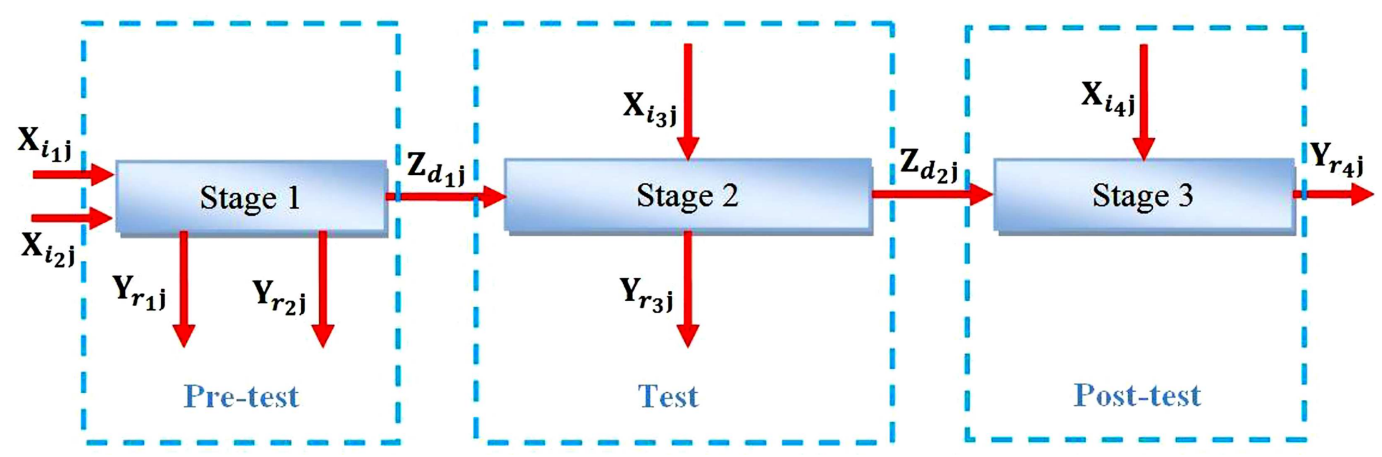

Figure 2. A network DEA of three stages series. 


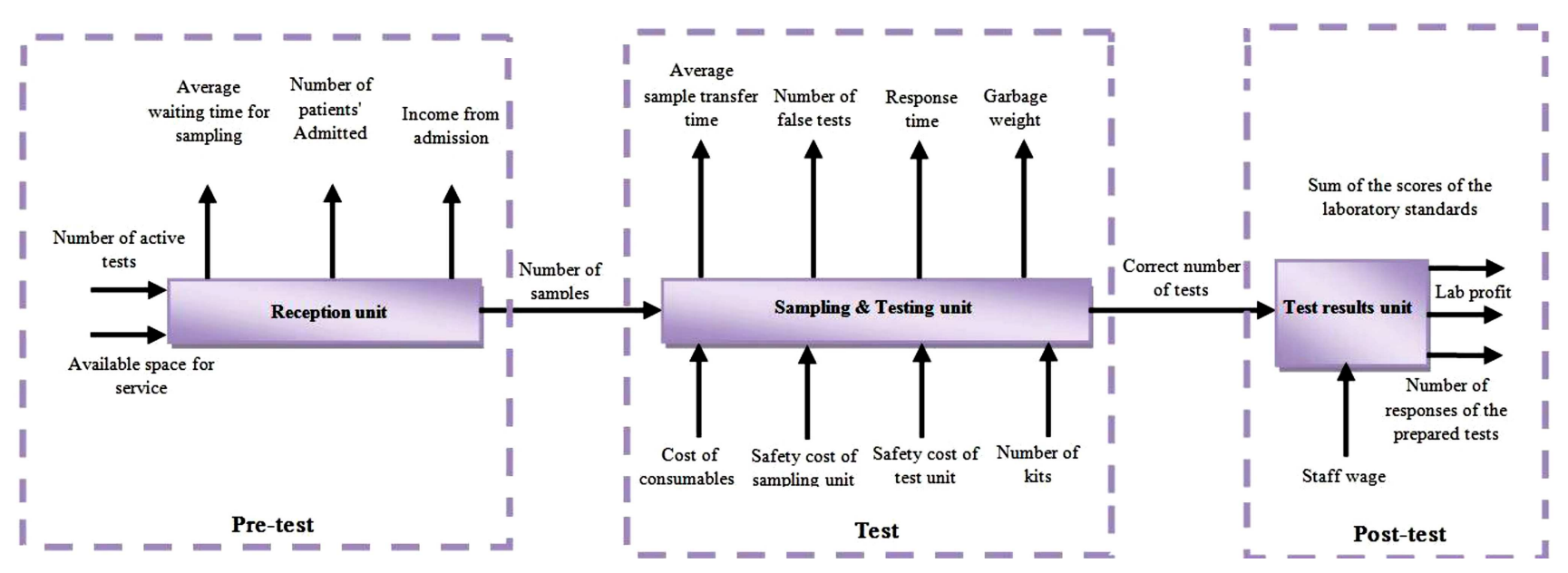

Figure 3. Three-stage network of a medical diagnostic laboratory.

are presented by $y_{r_{3} j}\left(r_{3}=1,2, \ldots, R_{3}\right)$. The additional input in the test results unit is represented by $x_{i_{4} j}\left(i_{4}=1,2, \ldots, I_{4}\right)$. Finally, the output of the test results unit is defined as $y_{r_{4} j}\left(r_{4}=1,2, \ldots, R_{4}\right)$.

Here, $v_{i_{1}}$ and $v_{i_{2}}$ are the weights of the inputs to the reception unit, and $z_{d_{1 j}}$ denotes the weight of the intermediate measures between the reception and sampling and testing units that can play a dual role in both reception and sampling and testing units. If we consider $z_{d_{1 j}}$ in the reception unit, $\eta_{d_{1}}$ denotes the weight of the output. Finally, $u_{r_{1}}$ and $u_{r_{2}}$ represent the weights on the outputs flowing from the reception unit. According to the three-stage network shown in Figure 3, the efficiency of the reception unit is determined by $\theta_{0}^{\text {Reception unit }}$

In the sampling and testing unit, $v_{i_{3}}$ and $u_{r_{3}}$ are the weights on the inputs and outputs, respectively, and $\eta_{d_{2}}$ denotes the weights on the intermediate measures in the sampling and testing unit. Given the dual role of $z_{d_{2} j}$ in the sampling and testing unit as well as the test results unit, we can define $\eta_{d_{2}}$ and $\eta_{d_{1}}$ as the weights associated with the outputs and inputs flowing from the sampling-and-testing unit, respectively. The efficiency of the sampling-and-testing unit is determined by $\theta_{0}^{\text {Sampling \& Testing unit }}$.

In the test results unit, $\eta_{d_{2}}$ and $u_{r_{4}}$ represent the weights on the inputs and outputs, respectively. In addition, $\eta_{d_{2}}$ shows the weights on the intermediate measures to the test results unit. Given that the intermediate measures play the dual role of $z_{d_{2} j}, \eta_{d_{2}}$ can be representative of the weights associated with the inputs flowing from the test results unit. The efficiency of the test results unit is determined by $\theta_{0}^{\text {Test results unit }}$.

The intermediate measures in this study were evaluated and re-modeled regardless of their dual role as either input of one stage or output of the next stage. Therefore, the same weights can be used for intermediate measures. This is a common assumption in DEA studies [34].
In the case of the network system given in Figure 2, all reception, sampling and testing, and test results units are connected by intermediate measures $z_{d_{1 j}}\left(d_{1}=1,2, \ldots, D_{1}\right)$ and $z_{d_{2 j}}\left(d_{2}=1,2, \ldots, D_{2}\right)$ in series. The overall efficiency of the system can be evaluated based on Eq. (1), conforming to the tandem system of Kao and Hwang [35]:

$$
\begin{aligned}
\theta_{0}^{\text {overall }}= & \max \theta_{0}^{\text {Reception unit }} \cdot \theta_{0}^{\text {Sampling \& Testing unt }} . \\
& . \theta_{0}^{\text {Test Results unit }}
\end{aligned}
$$

where $\theta_{0}^{\text {overall }}$ is the efficiency of the whole system. The overall efficiency $D M U_{0}$ can be achieved through the fractional program (Model (2)):

$$
\begin{aligned}
\theta_{0}^{\text {overall }}= & \max \frac{\sum_{d_{1}=1}^{D_{1}} \eta_{d_{1}} z_{d_{10}}+\sum_{r_{2}=1}^{R_{2}} u_{r_{2}} y_{r_{2} 0}-\sum_{r_{1}=1}^{R_{1}} u_{r_{1}} y_{r_{1} 0}}{\sum_{i_{1}=1}^{I_{1}} v_{i_{1}} x_{i_{1}}-\sum_{i_{2}=1}^{I_{2}} v_{i_{2}} x_{i_{2} 0}} \\
& \frac{\sum_{d_{2}=1}^{D_{2}} \eta_{d_{2}} z_{20}-\sum_{r_{3}=1}^{R_{3}} u_{r_{3}} y_{r_{3} 0}}{\sum_{i_{3}=1}^{I_{3}} v_{i_{3}} x_{i_{30}}+\sum_{d_{1}=1}^{D_{1}} \eta_{d_{1}} z_{d_{10}}} . \\
& \cdot \frac{\sum_{r_{4}=1}^{R_{4}} u_{r_{4}} y_{r_{4} 0}}{\sum_{i_{4}=1}^{I_{4}} v_{i_{4}} x_{i_{4} 0}+\sum_{d_{2}=1}^{D_{2}} \eta_{d_{2}} z_{d_{20}}}
\end{aligned}
$$

s.t.:

$$
\begin{gathered}
\frac{\sum_{d_{1}=1}^{D_{1}} \eta_{d_{1}} z_{d_{1 j}}+\sum_{r_{2}=1}^{R_{2}} u_{r_{2}} y_{r_{2} j}-\sum_{r_{1}=1}^{R_{1}} u_{r_{1}} y_{r_{1} j}}{\sum_{i_{1}=1}^{I_{1}} v_{i_{1}} x_{i_{1} j}-\sum_{i_{2}=1}^{I_{2}} v_{i_{2}} x_{i_{2} j}} \leq 1 \\
\quad j=1,2, \ldots, n
\end{gathered}
$$




$$
\begin{aligned}
& \frac{\sum_{d_{2}=1}^{D_{2}} \eta_{d_{2}} z_{d_{2}}-\sum_{r_{3}=1}^{R_{3}} u_{r_{3}} y_{r_{3} j}}{\sum_{i_{3}=1}^{I_{3}} v_{i_{3}} x_{i_{3} j}+\sum_{d_{1}=1}^{D_{1}} \eta_{d_{1}} z_{d_{1} j}} \leq 1, \quad j=1,2, \ldots, n, \\
& \frac{\sum_{r_{4}=1}^{R_{4}} u_{r_{4}} y_{r_{4} j}}{\sum_{i_{4}=1}^{I_{4}} v_{i_{4}} x_{i_{4}}+\sum_{d_{2}=1}^{D_{2}} \eta_{d_{2}} z_{d_{2} j}} \leq 1, \quad j=1,2, \ldots, n, \\
& \eta_{d_{1}}, \eta_{d_{2}}, u_{r_{1}}, u_{r_{2}}, u_{r_{3}}, u_{r_{4}}, v_{i_{1}}, v_{i_{2}}, v_{i_{3}}, v_{i_{4}} \geq \varepsilon ; \\
& d_{1}=1,2, \ldots, D_{1} ; d_{2}=1,2, \ldots, D_{2} ; r_{1}=1,2, \ldots, R_{1} ; \\
& r_{2}=1,2, \ldots, R_{2} ; r_{3}=1,2, \ldots, R_{3} ; r_{4}=1,2, \ldots, R_{4} ; \\
& i_{1}=1,2, \ldots, I_{1} ; i_{2}=1,2, \ldots, I_{2} ; i_{3}=1,2, \ldots, I_{3} ; \\
& i_{4}=1,2, \ldots, I_{4} .
\end{aligned}
$$

Since the performance level at all stages is less than one, Model (2) is considered a linear program. In this respect, a heuristic method is proposed in the next section to solve this model.

\subsubsection{Model solution and efficiency decomposition}

In the presence of additional inputs and outputs, Model (2) cannot be converted into a linear program. To solve this model, a hybrid approach was proposed to evaluate and analyze the performance of the network of the three-stage model. The objective function of Model (2) can be obtained through the multiplicative efficiency of the three-stage model obtained from:

$$
\begin{aligned}
\theta_{0}^{\text {overall }}= & \max \theta_{0}^{\text {Reception unit }} \cdot \theta_{0}^{\text {Sampling \& Testing unit }} . \\
& . \theta_{0}^{\text {Test Results unit }} .
\end{aligned}
$$

Therefore, the efficiency of the reception unit $\theta_{0}$ Reception unit and sampling-and-testing unit $\theta_{0}$ Sampling \&Testing unit can be obtained as two variables in the objective function which will change between the intervals $\left[0, \theta_{0}\right.$ Reception unit-max $]$ and $\left[0, \theta_{0}\right.$ Sampling \& Testining unit-max $]$, respectively. In addition, the optimal efficiency of the reception unit and the sampling-and-testing unit in Model (3) is obtained as follows:

$$
\begin{aligned}
& \theta_{0}^{\text {Reception unit }}=\theta_{0}^{\text {Reception unit }- \text { max }}-k_{1} \Delta \varepsilon, \\
& k_{1}=0,1,2, \ldots,\left[\frac{\theta_{0}^{\text {Reception unit }- \text { max }}}{\Delta} \varepsilon\right]+1, \\
& \theta_{0}^{\text {Sampling \& Testing unit }}=\theta_{0}^{\text {Sampling \& Testing unit }- \text { max }} \\
& -k_{2} \Delta \varepsilon, \\
& k_{2}=0,1,2, \ldots,\left[\frac{\theta_{0}^{\text {Sampling \& Testing unit }-\max }}{\Delta \varepsilon}\right]+1,
\end{aligned}
$$

where $\Delta \varepsilon$ is the step size that takes a very small value. Of note, the smaller the $\Delta \varepsilon$ value, the more precise the obtained results. Both $\theta_{0}^{\text {Reception unit-max }}$ and $\theta_{0}^{\text {Sampling \& Testing unit-max }}$ can be defined as the maximum efficiency of the first and second stages, respectively, calculated through Eq. (4) as shown in Box I. The maximum optimistic efficiency of the first and second stages in Eq. (4) can be obtained under conditions where the efficiency of all stages is less than one. Of note, all variables in Eq. (3) are non-negative. Through the transformation made by Charnes and Cooper [36], fractional programs were converted into linear programs by Models (5) and (6).

$$
\begin{aligned}
\theta_{0}^{\text {Reception unit }-\max }= & \max \sum_{d_{1}=1}^{D_{1}} \eta_{d_{1}} z_{d_{10}}+\sum_{r_{2}=1}^{R_{2}} u_{r_{2}} y_{r_{2} 0} \\
& -\sum_{r_{1}=1}^{R_{1}} u_{r_{1}} y_{r_{1} 0}
\end{aligned}
$$

$$
\begin{aligned}
\theta_{0}^{\text {Reception unit-max }}= & \max \left\{\theta_{0}^{\text {Reception unit }} \mid \theta_{j}^{\text {Reception unit }} \leq 1, \theta_{j}^{\text {Sampling \& Testing unit }} \leq 1, \theta_{j}^{\text {Test Results unit }} \leq 1,\right. \\
& j=1,2, \ldots, n\}
\end{aligned}
$$$$
\theta_{0}^{\text {Sampling \& Testing unit }-\max }=\max \left\{\theta_{0}^{\text {Sampling \& Testing unit }} \mid \theta_{j}^{\text {Reception unit }} \leq 1, \theta_{j}^{\text {Sampling \& Testing unit }} \leq 1,\right.
$$$$
\left.\theta_{j}^{\text {Test Results unit }} \leq 1, \quad j=1,2, \ldots, n\right\}
$$ 


$$
\begin{aligned}
& \text { s.t. : } \sum_{i_{1}=1}^{I_{1}} v_{i_{1}} x_{i_{10}}-\sum_{i_{2}=1}^{I_{2}} v_{i_{2}} x_{i_{2} 0} \\
& \sum_{d_{1}=1}^{D_{1}} \eta_{d_{1}} z_{d_{1 j}}+\sum_{r_{2}=1}^{R_{2}} u_{r_{2}} y_{r_{2} j}-\sum_{r_{1}=1}^{R_{1}} u_{r_{1}} y_{r_{1 j}} \\
& -\left(\sum_{i_{1}=1}^{I_{1}} v_{i_{1}} x_{i_{1} j}-\sum_{i_{2}=1}^{I_{2}} v_{i_{2}} x_{i_{2} j}\right) \leq 0, \quad j=1,2, \ldots, n, \\
& \sum_{d_{2}=1}^{D_{2}} \eta_{d_{2}} z_{d_{2} j}-\sum_{r_{3}=1}^{R_{3}} u_{r_{3}} y_{r_{3} j}-\left(\sum_{i_{3}=1}^{I_{3}} v_{i_{3}} x_{i_{3} j}\right. \\
& \left.+\sum_{d_{1}=1}^{D_{1}} \eta_{d_{1}} z_{d_{1 j}}\right) \leq 0, \quad j=1,2, \ldots, n \\
& \sum_{r_{4}=1}^{R_{4}} u_{r_{4}} y_{r_{4} j}-\left(\sum_{i_{4}=1}^{I_{4}} v_{i_{4}} x_{i_{4} j}+\sum_{d_{2}=1}^{D_{2}} \eta_{d_{2}} z_{d_{2} j}\right) \leq 0 \\
& j=1,2, \ldots, n, \\
& \eta_{d_{1}}, \eta_{d_{2}}, u_{r_{1}}, u_{r_{2}}, u_{r_{3}}, u_{r_{4}}, v_{i_{1}}, v_{i_{2}}, v_{i_{3}}, v_{i_{4}} \geq \varepsilon \\
& d_{1}=1,2, \ldots, D_{1} ; d_{2}=1,2, \ldots, D_{2} ; r_{1}=1,2, \ldots, R_{1} ; \\
& r_{2}=1,2, \ldots, R_{2} ; r_{3}=1,2, \ldots, R_{3} ; r_{4}=1,2, \ldots, R_{4} \\
& i_{1}=1,2, \ldots, I_{1} ; i_{2}=1 ; 2, \ldots, I_{2} ; i_{3}=1,2, \ldots, I_{3} ; \\
& i_{4}=1,2, \ldots, I_{4} \text {. } \\
& \theta_{0}^{\text {Sampling \& Testing unit }-\max }=\max \sum_{d_{2}=1}^{D_{2}} \eta_{d_{2}} z_{d_{2} 0} \\
& -\sum_{r_{3}=1}^{R_{3}} u_{r_{3}} y_{r_{3} 0} \\
& \sum_{i_{3}=1}^{I_{3}} v_{i_{3}} x_{i_{30}}+\sum_{d_{1}=1}^{D 1} \eta_{d_{1}} z_{d_{10}}=1 \\
& \sum_{d_{1}=1}^{D_{1}} \eta_{d_{1}} z_{d_{1} j}+\sum_{r_{2}=1}^{R_{2}} u_{r_{2}} y_{r_{2} j}-\sum_{r_{1}=1}^{R_{1}} u_{r_{1}} y_{r_{1} j} \\
& -\left(\sum_{i_{1}=1}^{I_{1}} v_{i_{1}} x_{i_{1 j}}-\sum_{i_{2}=1}^{I_{2}} v_{i_{2}} x_{i_{2} j}\right) \leq 0, \\
& j=1,2, \ldots, n, \\
& \sum_{d_{2}=1}^{D_{2}} \eta_{d_{2}} z_{d_{1 j}}-\sum_{r_{3}=1}^{R_{3}} u_{r_{3}} y_{r_{3} j}
\end{aligned}
$$

$$
\begin{gathered}
-\left(\sum_{i_{3}=1}^{I_{3}} v_{i_{3}} x_{i_{3}}+\sum_{d_{1}=1}^{D_{1}} \eta_{d_{1}} z_{d_{1} j}\right) \leq 0, \\
j=1,2, \ldots, n, \\
\sum_{r_{4}=1}^{R_{4}} u_{r_{4}} y_{r_{4} j}-\left(\sum_{i_{4}=1}^{I_{4}} v_{i_{4}} x_{i_{4}}+\sum_{d_{2}=1}^{D_{2}} \eta_{d_{2}} z_{d_{2} j}\right) \leq 0, \\
\quad j=1,2, \ldots, n, \\
\eta_{d_{1}}, \eta_{d_{2}}, u_{r_{1}}, u_{r_{2}}, u_{r_{3}}, u_{r_{4}}, v_{i_{1}}, v_{i_{2}}, v_{i_{3}}, v_{i_{4}} \geq \varepsilon ; \\
d_{1}=1,2, \ldots, D_{1} ; d_{2}=1,2, \ldots, D_{2} ; r_{1}=1,2, \ldots, R_{1} ; \\
r_{2}=1,2, \ldots, R_{2} ; r_{3}=1,2, \ldots, R_{3} ; r_{4}=1,2, \ldots, R_{4} ; \\
i_{1}=1,2, \ldots, I_{1} ; i_{2}=1,2, \ldots, I_{2} ; i_{3}=1,2, \ldots, I_{3} ; \\
i_{4}=1,2, \ldots, I_{4} .
\end{gathered}
$$

Followed by determining the values of:

$$
\theta_{0}^{\text {Reception unit-max }} \text { and } \theta_{0}^{\text {Sampling \& Testing unit-max }}
$$

through Models (5) and (6), Model (2) can be transformed into Model (7) as shown in Box II. In Model (7):

$$
\theta_{0}^{\text {Reception unit }} \text { and } \theta_{0}^{\text {Sampling \& Testing unit }}
$$

in the objective function are considered as two variables and two constraints which are representative of these two variables and their interval modifications. In Model (6), the efficiency of these two stages can be defined as the output-to-input ratio of each stage obtained from:

$$
\theta_{0}^{\text {Reception unit }}=\frac{o_{0}^{\text {Reception unit }}}{I_{0}^{\text {Reception unit }}}
$$

and:

$$
\theta_{0}^{\text {Sampling \& Testing unit }}=\frac{o_{0}^{\text {Sampling \& Testing unit }}}{I_{0}^{\text {Sampling \& Testing unit }}} .
$$

Given that Model (7) is a fractional model, the conversion of Charnes and Cooper [36] was employed and modified by the following linear program (Model (8)).

$$
\begin{gathered}
\theta_{0}^{\text {overall }}=\max \theta_{0}^{\text {Reception unit }} \cdot \theta_{0}^{\text {Sampling \& Testing unit }} \\
\cdot\left(\sum_{r_{4}=1}^{R_{4}} u_{r_{4}} y_{r_{4} 0}\right),
\end{gathered}
$$

s.t.: 


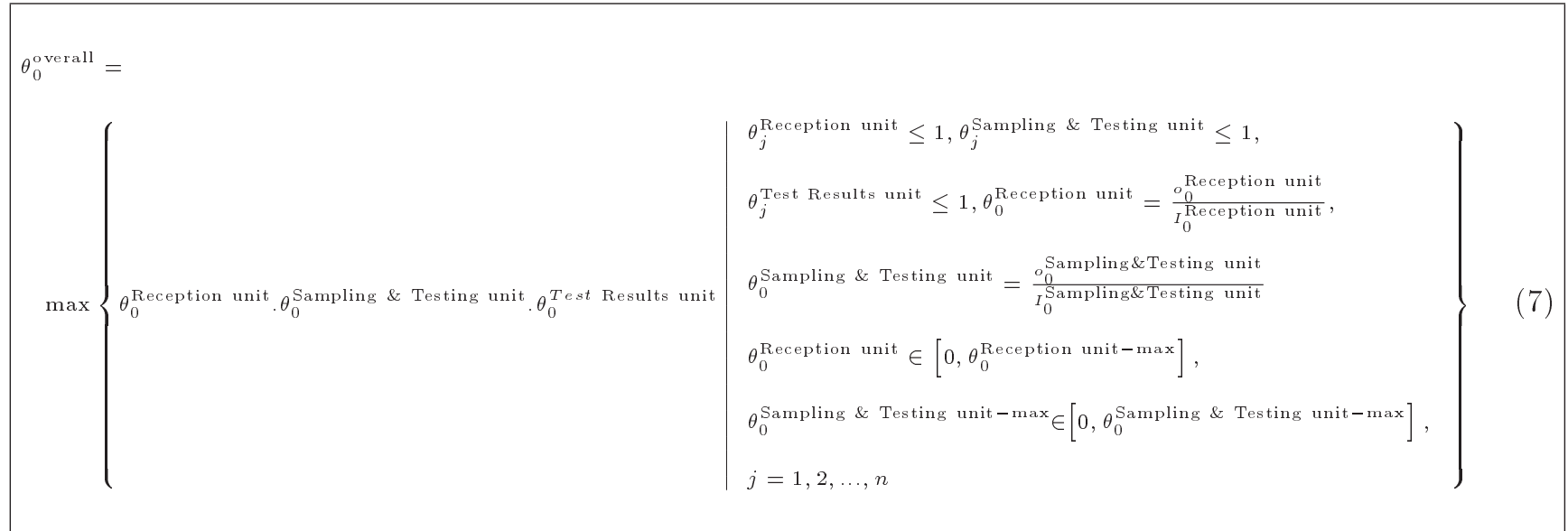

Box II

$$
\begin{aligned}
& \sum_{i_{4}=1}^{I_{4}} v_{i_{4}} x_{i_{4} 0}+\sum_{d_{2}=1}^{D_{2}} \eta_{d_{2}} z_{d_{2} 0}=1 \\
& \sum_{d_{1}=1}^{D_{1}} \eta_{d_{1}} z_{d_{1 j}}+\sum_{r_{2}=1}^{R_{2}} u_{r_{2}} y_{r_{2} j}-\sum_{r_{1}}^{R_{1}} u_{r_{1}} y_{r_{1} j} \\
& -\left(\sum_{i_{1}=1}^{I_{1}} v_{i_{1}} x_{i_{1} j}-\sum_{i_{2}=1}^{I_{2}} v_{i_{2}} x_{i_{2} j}\right) \leq 0, \\
& j=1,2, \ldots, n, \\
& \sum_{d_{2}=1}^{D_{2}} \eta_{d_{2}} z_{d_{2} j}+\sum_{r_{3}=1}^{R_{3}} u_{r_{3}} y_{r_{3} j} \\
& -\left(\sum_{i_{3}=1}^{I_{3}} v_{i_{3}} x_{i_{3} j}-\sum_{d_{1}=1}^{D_{1}} \eta_{d_{1}} z_{d_{1 j} j}\right) \leq 0 \\
& j=1,2, \ldots, n,
\end{aligned}
$$$$
\sum_{r_{4}=1}^{R_{4}} u_{r_{4}} y_{r_{4} j}-\left(\sum_{i_{4}=1}^{I_{4}} v_{i_{4}} x_{i_{4} j}-\sum_{d_{2}=1}^{D_{2}} \eta_{d_{2}} z_{d_{2} j}\right) \leq 0,
$$$$
j=1,2, \ldots, n,
$$$$
\sum_{d_{1}=1}^{D_{1}} \eta_{d_{1}} z_{d_{10}}+\sum_{r_{2}=1}^{R_{2}} u_{r_{2}} y_{r_{20}}-\sum_{r_{1}=1}^{R_{1}} u_{r_{1}} y_{r_{10}}
$$$$
-\theta_{0}^{\text {Reception unit }}\left(\sum_{i_{1}}^{I_{1}} v_{i_{1}} x_{i_{1} 0}-\sum_{i_{2}=1}^{I_{2}} v_{i_{2}} x_{i_{2} 0}\right)=0
$$

$$
\sum_{d_{2}=1}^{D_{2}} \eta_{d_{2}} z_{d_{2} 0}+\sum_{r_{3}=1}^{R_{3}} u_{r_{3}} y_{r_{3} 0}-\theta_{0}^{\text {Sampling \& Testing unit }}
$$

$$
\left(\sum_{i_{3}}^{I_{3}} v_{i_{3}} x_{i_{30}}-\sum_{d_{1}=1}^{D_{1}} \eta_{d_{1}} z_{d_{10}}\right)=0
$$

$\theta_{0}^{\text {Sampling \& Testing unit }} \in\left[0, \theta_{0}^{\text {Sampling \& Testing unit-max }}\right]$

$\eta_{d_{1}}, \eta_{d_{2}}, u_{r_{1}}, u_{r_{2}}, u_{r_{3}}, u_{r_{4}}, v_{i_{1}}, v_{i_{2}}, v_{i_{3}}, v_{i_{4}} \geq \varepsilon$

$d_{1}=1,2, \ldots, D_{1} ; d_{2}=1,2, \ldots, D_{2} ; r_{1}=1,2, \ldots, R_{1}$

$r_{2}=1,2, \ldots, R_{2} ; r_{3}=1,2, \ldots, R_{3} ; r_{4}=1,2, \ldots, R_{4}$

$i_{1}=1,2, \ldots, I_{1} ; i_{2}=1,2, \ldots, I_{2} ; i_{3}=1,2, \ldots, I_{3} ;$

$i_{4}=1,2, \ldots, I_{4}$.

If the values of $k_{1}$ and $k_{2}$ increase from (0) to a high level, the model can be solved each time with new $\theta_{0}^{\text {Reception unit }}$ and $\theta_{0}^{\text {Sampling \& Testing unit-max }}$. Then, the model can be solved for all modes of $k_{1}$ and $k_{2}$. In this regard, the model responses can be represented by $\theta_{0}^{\text {overall }}\left(k_{1}, k_{2}\right)$. A comparison of the overall values of $\theta_{0}^{\text {overall }}\left(k_{1}, k_{2}\right)$ reveals that the maximal efficiency of $\theta_{0}^{\text {overall }}\left(k_{1}, k_{2}\right)$ is defined as the performance of the network given in Figure 2 .

The proposed approach in this study was tested in three modes that took two stages each time. Given that the productivity of Figure 2 is unique, the results obtained from these three methods were remarkably approximate to each other. For this reason, one of these three conditions was considered to elaborate the proposed approach.

\section{Case study}

According to the statistics for the health reference laboratories, there are 5611 laboratories operating in Iran among which the shares of both public and private sectors are $57 \%$ and $43 \%$, respectively. In 
addition, there are 933 active laboratories in Tehran, constituting $16.7 \%$ of the total share of the country. Of these, $71 \%$ and $29 \%$ are managed by the private and public sectors, respectively. According to the statistics, unlike the number of laboratories in the country a majority of which are managed by the public sector, most of these labs are managed by private sectors in Tehran. Given the importance of the private sector in Tehran, our case study is greatly concerned about the private laboratories of Tehran. In this regard, the sample size in this study includes 25 medical diagnostic laboratories selected through cluster sampling from private laboratories in Tehran.

\subsection{Inputs and outputs}

This subsection assesses the performance of private medical diagnostic laboratories in Tehran. Medical diagnostic laboratories go through three main processes: the pre-test, testing, post-test processes, as shown in Figure 3.

The reception unit is the only component of the pre-test process with only two inputs, i.e., the number of active experiments $\left(x_{1}\right)$ and available space for service $\left(x_{2}\right)$, and some outputs including the average waiting time for sampling $\left(y_{1}\right)$, income from admission (economic criterion) $\left(y_{2}\right)$, and income from admission (economic criterion) $\left(y_{3}\right)$. The number of samples $\left(z_{1}\right)$ is determined based on the reception, sampling, and testing units. The sampling-and-testing units comprise the testing process. Together, they have four inputs, i.e., the cost of consumables (economic criterion) $\left(x_{3}\right)$, safety cost of the sampling unit (social criterion) $\left(x_{4}\right)$, safety cost of testing unit (social criterion) $\left(x_{5}\right)$, and number of kits $\left(x_{6}\right)$. Their outputs are the average sample transfer time $\left(y_{4}\right)$, number of false tests $\left(y_{5}\right)$, test response time $\left(y_{6}\right)$, and garbage weight (environmental criterion) $\left(y_{7}\right)$. The reception and the sampling and testing units are linked in series. The intermediate measure of the sampling and testing units and the test unit is defined as the correct number of tests $\left(z_{2}\right)$. The post-test process involves just one stage, i.e., the test results stage. Both the results and the sampling and testing units are linked in series. The test results unit has three outputs namely the number of the responses of the prepared tests $\left(y_{8}\right)$, sum of the scores of the laboratory standards $\left(y_{9}\right)$, and Lab Profit (economic criterion) $\left(y_{10}\right)$. The staff wage $\left(x_{7}\right)$ (economic criterion) is regarded as the additional input for the results test unit.

\section{Results}

In accordance with experts' opinions, the step size in this model is assumed to be $\Delta \varepsilon=0.01$. In the following, the overall efficiency as well as the efficiency of the stages in Figure 2 are obtained based on Model (7). For this purpose, first, the performance of the first and second stages should be evaluated based on Model (3). Then, the efficiency of Model (8) is determined by changing the variables $k_{1}$ and $k_{2}$ in Eq. (4). Table (6) lists the values for the overall efficiency as well as that of the three stages called the reception, sampling and testing, and test results units of medical diagnostic laboratories in Tehran.

The values of $k_{1}$ and $k_{2}$ were taken into account to find the optimal values of the network introduced in Figure 2 and to determine the time when the first and second stages reach their maximum values. For this reason, all values of $k_{1}$ and $k_{2}$ are disregarded. The second column of Table 6 illustrates the overall efficiency of the medical diagnostic laboratory units in grey. According to the results, among all of labs, only one is efficient, while other 24 ones are inefficient. In addition, the average efficiency values of the reception, sampling and testing, and test results units were measured as $0.74,0.99$, and 0.83 , respectively.

Obviously, the discriminatory power of the proposed NDEA model in health systems is greater than that of traditional DEA models. Given that this research proposes a heuristic model to convert the multiplicative NDEA approach into an equivalent linear program that not only simplifies complex calculations but also increases the accuracy of the performance values. In addition, the proposed NDEA model can be used for ranking of all stages, while the traditional DEA model is only able to rank DMUs, thus failing to offer the real ranking. In the previous studies conducted in different areas of health services, the performance evaluation of the internal structure based on the undesirable sustainability indicators has been neglected, hence less accuracy of the obtained results. Due to the prevalence of chronic epidemic diseases in the present age, real ranking is of particular importance in obtaining flexible and adjustable results to be used by the managers of medical diagnostic laboratory units. In this respect, the proposed model can provide a functional platform for managers to make correct decisions.

Based on the results, the final ranking of laboratories is as follows:

$$
\begin{aligned}
& L a b_{22}>L a b_{18}>L a b_{13}>L a b_{3}>L a b_{20}> \\
& L a b_{21}>L a b_{10}>L a b_{15}>L a b_{19}>L a b_{11}> \\
& L a b_{7}>L a b_{6}>L a b_{4}>L a b_{16}>L a b_{1}> \\
& L a b_{17}>L a b_{14}>L a b_{2}>L a b_{5}>L a b_{24}> \\
& L a b_{25}>L a b_{9}>L a b_{23}>L a b_{12}>L a b_{8} .
\end{aligned}
$$

The " $>$ " symbol is indicative of better performance. According to the findings of this study, most private 
Table 6. Comparison of overall efficiency and efficiency of four stages for 25 medical diagnostic laboratories in 2018.

\begin{tabular}{|c|c|c|c|c|c|c|}
\hline Lab & $\theta^{\text {overall }}$ & $\theta^{\text {Reception unit }}$ & $\theta^{\text {Sampling \& Testing unit }}$ & $\theta^{\text {Test Results unit }}$ & $K_{1}$ & $K_{2}$ \\
\hline 1 & 0.79044 & 1 & 1 & 0.79044 & 0 & 0 \\
\hline 2 & 0.74755 & 1 & 1 & 0.74755 & 0 & 0 \\
\hline 3 & 1 & 1 & 0.9367 & 0.9367 & 0 & 0 \\
\hline 4 & 0.80058 & 0.99195 & 0.53988 & 0.42874 & 0 & 0 \\
\hline 5 & 0.74256 & 1 & 1 & 0.74256 & 0 & 0 \\
\hline 6 & 0.87083 & 1 & 0.82592 & 0.71924 & 0 & 0 \\
\hline 7 & 0.88457 & 1 & 1 & 0.88457 & 0 & 0 \\
\hline 8 & 0.44298 & 1 & 0.81647 & 0.36168 & 0 & 0 \\
\hline 9 & 0.67675 & 0.99738 & 0.75611 & 0.51036 & 0 & 0 \\
\hline 10 & 0.99999 & 0.99709 & 0.43292 & 0.43166 & 0 & 0 \\
\hline 11 & 0.89141 & 1 & 0.89103 & 0.79428 & 0 & 0 \\
\hline 12 & 0.62505 & 0.99599 & 0.36656 & 0.2282 & 0 & 0 \\
\hline 13 & 1 & 0.99037 & 1 & 0.99037 & 0 & 0 \\
\hline 14 & 0.75534 & 1 & 0.66139 & 0.49958 & 0 & 0 \\
\hline 15 & 0.92763 & 1 & 0.43943 & 0.40763 & 0 & 0 \\
\hline 16 & 0.79536 & 1 & 1 & 0.79536 & 0 & 0 \\
\hline 17 & 0.78145 & 1 & 0.59759 & 0.46699 & 0 & 0 \\
\hline 18 & 1 & 0.99216 & 1 & 0.99216 & 0 & 0 \\
\hline 19 & 0.89967 & 0.97776 & 1 & 0.87966 & 0 & 0 \\
\hline 20 & 1 & 0.99079 & 0.36925 & 0.36585 & 0 & 0 \\
\hline 21 & 1 & 0.99236 & 0.15403 & 0.15362 & 0 & 0 \\
\hline 22 & 1 & 1 & 1 & 1 & 0 & 0 \\
\hline 23 & 0.65196 & 0.99456 & 0.7256 & 0.47049 & 0 & 0 \\
\hline 24 & 0.69152 & 0.99348 & 0.53293 & 0.36613 & 0 & 0 \\
\hline 25 & 0.67739 & 1 & 0.41965 & 0.28427 & 0 & 0 \\
\hline
\end{tabular}

labs in Tehran were found to be inefficient in terms of their poor performance in several cases. First, one of the most important sources of municipal wastes production is hospitals, health centers, physicians, clinics, and medical diagnostic laboratories. Among them, the laboratories produce large amounts of infectious waste that seriously threaten both health and environment. Releasing this waste into the environment can cause and transmit a variety of diseases such as Hepatitis B, C, and AIDS. This is the main reason why the performance of laboratories in proper management of waste is of significance. Second, the standards and criteria should be analyzed based on which any laboratory system should be upgraded. As a result, quality management achievements in the labs bring about several advantages such as accuracy enhancement of the results obtained by the labs, guarantee of continuous calibration of lab equipment, standardization of the procedures for management of laboratories, and improvement in the customeroriented level of laboratories. Third, an important factor that differentiates and excels a laboratory is its capability of extensive coverage of services. In this regard, increasing the geographical coverage of services of each laboratory is important. Fourth, factors including currency fluctuations, price increases of kits, and cost of implementing quality standards indicate that the laboratories should control and manage costs. For instance, on average, $45 \%$ of the total cost required is related to the consumables in each laboratory, thus emphasizing the significant role of the cost management in efficiency enhancement. Followed by the reasons why the laboratories are required to enhance their performance efficiency, several solutions to this problem are given in the following:

1. Separation of the laboratory wastes in the place of production, collection and labeling, transportation 
to a safe place, packing, temporary storage, transportation from the place of production and loading, and final disposal stage. All steps are designed according to the performance and extent of the activities of each laboratory. All staff members should be educated about the procedures in written instructions;

2. Investigation of the factors, status determination of the laboratory, classification of the results based on their weaknesses and strengths, and gap determination between the existing and desired situations may provide appropriate and effective strategies for standardizing the laboratories;

3. Given the growing diversity and capacity of the experiments, provision of services to smaller laboratories is one of the policies successful labs take. Application of sampling units and use of information and communication technology are also two of the requirements of the coverage of services;

4. The operation management approach based on identifying and eliminating the unnecessary points should be taken into consideration, which in turn would reduce additional laboratory costs and increase productivity.

\section{Conclusion}

Laboratory centers constitute an important part of many health care systems and research organizations. Since the performance of such clinical and research laboratories plays a vital role in determining the quality and efficiency of health care systems and research activities, the need for solutions is felt to evaluate and improve their performance that has attracted the attention of the world's scientific and professional communities for many years. The performance measurement at laboratory centers is necessary for managers and authorities in health care centers and research organizations through which they can make some improvement and increase productivity in their organizations by identifying their strengths and weaknesses.

Any performance evaluation program aims to increase efficiency and improve effectiveness upon assisting the laboratories in developing their skills and knowledge to meet the future requirements of the work units. It is important that the tasks be done properly at laboratories to improve the quality of the test results and promote the effectiveness of the services and research achievements. Effectiveness of services at clinical laboratories leads to quick illness diagnosis and saving of the lives of patients. In addition, effectiveness of their research accomplishments and their commercialization would lead to the growth and self-sufficiency of research organizations. In this regard, the current study proposed a multiplicative Network Data Envelopment Analysis (NDEA) model based on a heuristic model to convert the NDEA approach into an equivalent linear program. The proposed method enjoys several advantages. For instance, it makes the ranking method more accurate that is necessary, especially in health service departments. In addition, the efficiency of each stage in this method can be independently examined based on which managers hold different views to evaluate the performance of the units. Moreover, decision-makers can obtain information about all the performance aspects, thus making the right decisions. Therefore, the proposed model, in addition to assessing the performance of DecisionMaking Units (DMUs), could also rank the labs more accurately. While the factors of sustainable development in health care services have been neglected in the previous studies, the sustainability factors in this paper were classified into three levels of economic, social, and environmental indicators. Given the significant role of the undesirable data in the actual performance of medical diagnostic laboratories, undesirable factors along with sustainable development were identified and investigated with regard to these indicators.

In order to validate the proposed multiplicative NDEA model, a real case study in Iran was taken into consideration to determine the effectiveness of medical diagnostic laboratories. For this purpose, first, a three-stage network characterized by a series of medical diagnostic labs in the real-world mode was simulated. This network model comprised three main laboratory processes, namely the pre-test, test, and post-test processes. The pre-testing, testing, and post-test processes contained the reception, sampling and testing, and test results units, respectively. The proposed model could be considered an innovative model since no similar research was found in the field of medical diagnostic laboratories as a network analysis.

For future research, the results of this research are made accessible to managers for the purpose of assistance in order to improve laboratory services through appropriate approaches. Due to many complexities and problems in collecting data, it is suggested that future research on modeling be done with imprecise data. Further, since the activities of an enterprise such as medical diagnostic laboratories are ongoing over a period of time, the cross-sectional efficiency assessment cannot provide a realistic answer to the problem of the performance assessment of laboratories. In this respect, network analysis in a dynamic mode, such as window NDEA model, is recommended.

\section{References}

1. Nolte, E. and McKee, M. "Measuring the health of nations: analysis of mortality amenable to health care", 
Journal of Epidemiology \& Community Health, 58(4), pp. 321-326 (2004). https://jech.bmj.com/content/ $58 / 4 / 326$.short

2. The European Health Report 2009: Health and Health Systems, Copenhagen, WHO Regional Office for Europe.

3. Solnica, B., Dabrowska, M., and Sypniewska, G. "Laboratory medicine as a profession and clinical scienceHow to perform both of them well? ", EJIFCC, 21(3), p. 53 (2010).

4. Engau, A. "Proper efficiency and tradeoffs in multiple criteria and stochastic optimization", Mathematics of Operations Research, 42(1), pp. 119-134 (2016).

5. Charnes, A., Cooper, W.W., and Rhodes, E. "Measuring the efficiency of decision making units", European Journal of Operational Research, 2(6), pp. 429-444 (1978).

6. Kao, C. "Network data envelopment analysis: A review", European Journal of Operational Research, 239(1), pp. 1-16 (2014).

7. Wei, Q. and Yan, H. "A data envelopment analysis (DEA) evaluation method based on sample decision making units", International Journal of Information Technology \& Decision Making, 9(04) pp. 601-624 (2010).

8. Färe, R. and Whittaker, G. "An intermediate input model of dairy production using complex survey data", Journal of Agricultural Economics, 46(2), pp. 201-213 (1995).

9. Lewis, H.F. and Sexton, T.R. "Network DEA: efficiency analysis of organizations with complex internal structure", Computers \& Operations Research, 3(9), pp. 1365-1410 (2004).

10. Färe, R., Grosskopf, S., Lovell, C.K., et al. "Multilateral productivity comparisons when some outputs are undesirable: a nonparametric approach", The Review of Economics and Statistics, 71(1), pp. 90-98 (1989).

11. Rosko, M.D. and Mutter, R.L. "What have we learned from the application of stochastic frontier analysis to US hospitals?", Medical Care Research and Review, 68(1-suppl), pp. 75S-100S (2011).

12. Nayar, P. and Ozcan, Y.A. "Data envelopment analysis comparison of hospital efficiency and quality", Journal of Medical Systems, 32(3), pp. 193-199 (2008).

13. Audibert, M., Mathonnat, J., Pelissier, A., et al. "Health insurance reform and efficiency of township hospitals in rural China: An analysis from survey data", China Economic Review, 27, pp. 326-338 (2013).

14. Varabyova, Y. and Schreyögg, J. "International comparisons of the technical efficiency of the hospital sector: panel data analysis of OECD countries using parametric and non-parametric approaches", Health Policy, 112(1-2), pp. 70-79 (2013).

15. Leleu, H., Moises, J., and Valdmanis, V.G. "How do payer mix and technical inefficiency affect hospital profit? A weighted DEA approach", Operations Research for Health Care, 3(4), pp. 231-237 (2014).

16. Popescu, C., Asandului, L., and Fatulescu, P. "A data envelopment analysis for evaluating Romania's health system", Procedia-Social and Behavioral Sciences, 109, pp. 1185-1189 (2014).

17. Asandului, L., Roman, M., and Fatulescu, P. "The efficiency of healthcare systems in Europe: A data envelopment analysis approach", Procedia Economics and Finance, 10, pp. 261-268 (2014).

18. Al-Refaie, A., Fouad, R.H., and Li, M.H. "Applying simulation and DEA to improve performance of emergency department in a Jordanian hospital", Simulation Modelling Practice and Theory, 41, pp. 59-72 (2014).

19. Chowdhury, H. and Zelenyuk, V. "Performance of hospital services in Ontario: DEA with truncated regression approach", Omega, 63, pp. 111-122 (2016).

20. Campos, M.S., Fernández-Montes, A., and Gavilan, J.M. "Public resource usage in health systems: a data envelopment analysis of the efficiency of health systems of autonomous communities in Spain", Public Health, 138, pp. 33-40 (2016).

21. Johannessen, K.A., Kittelsen, S.A., and Hagen, T.P. "Assessing physician productivity following Norwegian hospital reform: A panel and data envelopment analysis", Social Science \& Medicine, 175, pp. 117-126 (2017).

22. Khushalani, J. and Ozcan, Y.A. "Are hospitals producing quality care efficiently? An analysis using Dynamic Network Data Envelopment Analysis (DEA)", SocioEconomic Planning Sciences, 60, pp. 15-23 (2017).

23. Patra, A. and Ray, P.K. "Measurement of efficiency and productivity growth of hospital systems: a Indian case study", In Healthcare Systems Management: Methodologies and Applications, pp. 13-22, Springer, Singapore (2018).

24. Şahin, B. and Ílgün, G. "Assessment of the efficiency of dental services in Turkey", Health Policy and Technology, 7(2), pp. 173-181 (2018).

25. Haghighi, S.M. and Torabi, S.A. "A novel mixed sustainability-resilience framework for evaluating hospital information systems", International Journal of Medical Informatics, 118, pp. 16-28 (2018).

26. Peykani, P., Mohammadi, E., Emrouznejad, A., et al. "Fuzzy data envelopment analysis: An adjustable approach", Expert Systems with Applications, 136, pp. 439-452 (2019).

27. Thorsen, M.L., Thorsen, A., and McGarvey, R. "Operational efficiency, patient composition and regional context of US health centers: Associations with access to early prenatal care and low birth weight", Social Science \& Medicine, 226, pp. 143-152 (2019).

28. Abolghasem, S., Toloo, M., and Amézquita, S. "A dataset of healthcare systems for cross-efficiency evaluation in the presence of flexible measure", Data in Brief, 25, p. 104239 (2019). 
29. Chawla, R., Goswami, B., and Singh, B. "Evaluating laboratory performance with quality indicators", Laboratory Medicine, 41(5), pp. 297-300 (2010).

30. Bakar, A.H.A., Hakim, I.L., and Chong, S.C. "Measuring supply chain performance among public hospital laboratories", International Journal of Productivity and Performance Management, 59(1), pp. 75-79 (2010).

31. Gumus, A.T. "Evaluation of hazardous waste transportation firms by using a two step fuzzy-AHP and TOPSIS methodology", Expert Systems with Applications, 36(2), pp. 4067-4074 (2009).

32. Lin, M.C., Wang, C.C., and Chen, M.S. "Using AHP and TOPSIS approaches in customer-driven product design process", Computers in Industry, 59(1), pp. 1731 (2008).

33. Chen, C.T. "Extensions of the TOPSIS for group decision-making under fuzzy environment", Fuzzy Sets and Systems, 114(1), pp. 1-9 (2000).

34. Aviles-Sacoto, S., Cook, W.D., and Imanirad, R. "Two-stage network DEA: when intermediate measures can be treated as outputs from the second stage", Journal of the Operational Research Society, 66(11), pp. 1868-1877 (2015).

35. Kao, C. and Hwang, S.N. "Efficiency decomposition in two-stage data envelopment analysis: An application to non-life insurance companies in Taiwan", European Journal of Operational Research, 185(1), pp. 418-429 (2008).

36. Charnes, A. and Cooper, W.W. "Programming with linear fractional functional", Naval Research Logistics Quarterly, 9(3-4), pp. 181-186 (1962).

\section{Biographies}

Niloufar Ghafari Someh is a $\mathrm{PhD}$ candidate in Industrial Engineering from Science and Research Branch, Islamic Azad University. Her PhD thesis focuses on Data Envelopment Analysis. Her research interests include Data Envelopment Analysis (DEA), supply chain management, and system optimization.

Mir Saman Pishvaee is an Associate Professor of Industrial Engineering at Iran University of Science and Technology. He received his PhD from University of Tehran in 2012 and has initiated his career as a faculty member at SIE since 2013. His research vision is mainly concentrated on supply chain management and system optimization. He teaches courses related to procurement and supply management, robust optimization, system analysis and design, and operations management courses.

Seyed Jafar Sadjadi received his $\mathrm{PhD}$ from University of Waterloo, Canada. His research interests include solving different classes of optimization problems in industrial engineering areas such as supply chain management, portfolio optimization, optimal pricing, etc. He has been working at Iran University of Science and Technology since 2001.

Roya Soltani is currently an Assistant Professor at the Department of Industrial Engineering, KHATAM University, Tehran, Iran. Her research interests include Data Envelopment Analysis (DEA), decision theory, fuzzy theory, evolutionary algorithms, and reliability. 